\title{
To Assess the Knowledge and Practice of Home Care Regarding Post Craniotomy Care among Caregivers of Craniotomy Patients
}

\author{
Shakib H. Sheikh ${ }^{1}$, Vaishali Moreshwar Tembhare ${ }^{2}$ \\ 1, 2 Department of Medical Surgical Nursing, Srimati Radhikabai Meghe Memorial College of Nursing, \\ Sawangi (Meghe), Wardha, Maharashtra, India.
}

\section{ABSTRACT}

\section{BACKGROUND}

After the initial phase of hospitalization and recovery, most patients return to home to live in community with numerous physical, psychological, mental, social, and spiritual health disabilities. Those conditions prohibit the individual from participating in the community independently and efficiently. Around three fourths of patients tend to receive help from family members for daily living activities. So, family caregivers play a significant part, since they bear a large portion of the cost of home care. The aim of this research was to assess the knowledge and practices among the caregivers of post craniotomy patients regarding home care of craniotomy patients.

\section{METHODS}

A descriptive exploratory study was undertaken on 36 purposively selected caregivers of patients undergoing craniotomy in Wardha district. Data were collected by using structured questionnaire and observational checklist during the month June 2020.

\section{RESULTS}

Awareness level with age in craniotomy-patient care givers years was assessed. ' $F$ ' value was $2.84(\mathrm{DF}=3,32)$, lower than measured 'F' i.e. 8.03 at a significant point of $5 \%$. Also, the measured ' $\mathrm{p}$ ' $=0.0001$ which was slightly less than the appropriate significance point. Hence, it is perceived that age is statistically correlated with their information score in years of craniotomy caregiver's patients. Knowledge level with the educational status of craniotomy-patient caregivers was assessed. ' $F$ ' value was $2.53(\mathrm{DF}=5.30$ ), lower than ' $\mathrm{F}$ ' meaning level of 5.30 at $5 \%$. Even the measured ' $\mathrm{p}$ ' = 0.001 was slightly lower than the appropriate significance point. Therefore, it is perceived that the educational status of craniotomy patient's caregivers is statistically correlated with their knowledge score. Knowledge score with the occupation of caregivers of craniotomy patients was assessed. 'F' value was 2.61 (DF $=4,31$ ), far lower ' $F$ ' i.e. 4.92 at a significance point of $5 \%$. Furthermore, the measured ' $p$ ' $=0.002$ which was slightly less than the appropriate significance point. Thus, it is perceived that occupation of craniotomy patient's caregivers is statistically correlated with their score of knowledge. Practice association scores with a relationship with caregiver craniotomy patients were determined. ' $F$ ' value was 2.53 $(\mathrm{DF}=5,30)$, less than the measured significance amount of ' $F$ ' i.e. 2.93 at 5 percent. Furthermore, the measured ' $\mathrm{p}$ ' $=0.028$ was lower than the acceptable significance level. Hence it is perceived that the relationship with caregivers' craniotomy patients is associated with their practice score statistically.

\section{CONCLUSIONS}

Craniotomy caregivers were not having 100 per cent knowledge of craniotomy care. It is interpreted that an important significant relationship between knowledge score with selected demographic variables was found in the age, education, and occupation. And it is considered that an important significant relationship between practice score and selected demographic variables was found in relation with craniotomy patients.
Corresponding Author Ms. Vaishali Moreshwar Tembhare, Department of Medical Surgical Nursing, Srimati Radhikabai Meghe Memorial College of Nursing, Sawangi (Meghe), Wardha, Maharashtra, India. E-mail: tembhare.vaishali@gmail.com

DOI: $10.14260 /$ jemds/2020/742

How to Cite This Article:

Sheikh SH, Tembhare VM. To assess the knowledge and practice of home care regarding post craniotomy care among caregivers of craniotomy patients. Evolution Med Dent Sci 2020;9(45):33773381, DOI: $10.14260 /$ jemds/2020/742

Submission 05-08-2020,

Peer Review 28-09-2020,

Acceptance 05-10-2020,

Published 09-11-2020.

Copyright (C) 2020 Shakib H. Sheikh et al. This is an open access article distributed under Creative Commons Attribution License [Attribution 4.0 International (CC $B Y 4.0)]$

\section{KEY WORDS}

Craniotomy, Knowledge, Practice, Home Care 


\section{BACKGROUND}

A craniotomy is a surgical procedure that momentarily removes a bone flap from the skull to reach the brain. Craniotomies are also a vital procedure in patients with brain damage or Traumatic Brain Injury (TBI) and can often allow doctors to surgically implant deep brain stimulants to treat Parkinson's disease, epilepsy, and cerebellar tremor. ${ }^{1}$

It profoundly affects physiological as well as psychological functions. ${ }^{2}$ Data suggests that some of India's leading sites saw over 40,000 neurology patients every year between the years 2003 and 2006. ${ }^{3}$ The diagnosis and treatment of neurological problems need a high level of accuracy and timing that will assess the prognosis and even decide the quality of life of a patient. A big cause of mortality was neurological diseases. For that mortality and morbidity, both disease-specific and other factors need to be given attention. A neurological disorder presents a major challenge for the person, the family, and the caregiver whether they are a patient, a family member, or a significant other. Neurosurgery is one of the main treatment schemes for neurological disorders. ${ }^{2}$

Neurosurgery in India has improved tremendously. Today we are in the era of minimally invasive neurosurgery 4 . Neurosurgical development in India in the last 55 years has almost parallel with the country's success of " 55 years of independence." This mainly focused on the most fragile and vital organs of the body. Since corrections of the neuro system disorders long considered by the public are unlikely, the patient is typically apprehensive of the outcome. So she or he should be told in every possible way. ${ }^{5}$

Many may have complex medical and social issues inside a neurosurgical ward. ${ }^{6}$ Whatever the cause, the general preoperative and postoperative nursing treatment is identical to that of the patient undergoing cranial surgery. Nurses can play a critical role in fostering a transition to a more patientcare-focused atmosphere in outpatient neurosurgery. Nurses have immense capacity to improve satisfaction and results by offering information and support to patients and their families for patients undergoing these procedures. The keys to that complication and readmission are adequate planning and their post-operative care. ${ }^{7}$

Craniotomy complications include epilepsy, hemiplegia or hemiparesis, cancer, stroke, DVT (Deep Vein Thrombosis), pulmonary embolism, which may result in permanent brain damage. After the initial phase of hospitalization and recovery, several patients return home to live in a group with various physical, psychological, mental, social, and spiritual health disabilities. Such conditions preclude the individual from living in the community individually and efficiently. Approximately three-fourths of patients tend to seek support from family members for the daily living activities. Family caregivers thus play a significant role, as they born a large portion of the cost of home care. ${ }^{8}$

This is why it is important to help family careers and their ability to provide care at home. A key concern is that increased reliance on family members without an adequate understanding of their own support needs may have a detrimental effect on family caregivers' capacity to provide care in the future and contribute to even greater mental, physical, and financial strains. This adverse impact on the caregiver would potentially affect the quality of treatment of the caregiver and the quality of life of the caregiver, and the rest of the family. Research has shown that unrelieved caregiver stress, fatigue, financial problems, and other carerelated pressures are major contributing factors to institutionalization, often leading to higher public spending on nursing expenses. ${ }^{9}$

\section{METHODS}

An exploratory descriptive research was undertaken on the basis of prevalence. 36 purposively selected caregivers of patients undergoing craniotomy in Wardha district were enrolled and non-probability convenient sampling technique was used in the study, data was collected by using structured questionnaire and observational checklist during the month of June 2020. Caregivers previously exposed to such study, those who are already having practice regarding post-operative craniotomy management were included in the study. Caregivers who are health professional were excluded. A questionnaire was created in the most commonly spoken Marathi languages in the area. Participation was voluntary at the report. Participants answered the questionnaires themselves anonymously.

A tool was devised through several steps of item generation, reduction, weightage, pilot testing of the tool and validating the tool. The content validity was determined after the opinion of 10 expert's in the field of medical-surgical nursing and neurosurgery. Tool validation included measurement of inter-observer reliability; and generation of criterion related, construct related and content related validity. The tool was later revised by English-language expert and then translated into Marathi language by language experts without altering the tool's meaning. This is true and appropriate for craniotomy patients' caregivers.

The Institutional Ethical Committee of the Datta Meghe, Institute of Medical Sciences,' Deemed to be University sanctioned approval for conducting the research study was obtained. The findings were summarized by concentrations and percentages, categorically. The program used in the study was SPSS 24.0 and the edition of Graph Pad Prism 7.0 and p < 0.05 is regarded as a degree of significance.

The questionnaire consisted of parts for acquiring demographic information and relevant questions related to the knowledge about craniotomy treatment of the participants. A home-based analytical guide for postcraniotomy treatment was given.

To accomplish the objective of the study the investigator collected data from 36 caregivers by a self-prepared questionnaire including 16 questions based on various aspects of home care after craniotomy. Each correct answer carries 1 mark, and 0 has been given for the wrong response. Knowledge was graded from poor knowledge to excellent knowledge based on scores. The minimum score was zero (0) and the maximum score was sixteen (16). Based on the total number of correct responses, the degree of knowledge was classified as poor 0 - $25 \%$ (1 - 4), average 26 - $50 \%$ (5 - 8), good 51 - $75 \%$ ( 9 - 12), excellent $76-100 \%$ (13 - 16).

Observational checklist consists of 16 steps that have to be performed by caregivers while administering craniotomy care to craniotomy patients. For a right answer, score 1 was given, score 0 was given for the wrong answer; the response was graded from poor to better based on score. Practice rates were 
graded as poor $(0-20$ percent), average (21- 40 percent), good ( $41-60$ percent), best ( $61-80$ percent) and better ( 81 - 100 percent), based on the total number of correct responses.

\section{Statistical Analysis}

Analysis of the data was done by using descriptive and inferential statistics both. Descriptive statistics was used to describe the basic features of the data in a study and the inferential statistics was used to make inferences from our data to more general conditions the percentage-wise distribution of the caregivers of craniotomy patients about their demographic characteristics was calculated. The statistical tests used for the analysis of the result were: Students unpaired t-test, one-way ANOVA, Pearson' correlation coefficient, and reliability analysis.

A suitable sample was drawn from the study population of 36 subjects who stayed in the Wardha district. The data was collected to classify sample characteristics including age, gender, education, occupation, and patient relationship.

\begin{tabular}{|c|c|c|}
\hline \multicolumn{3}{|c|}{ RESULTS } \\
\hline Demographic Variables & No. of Caregivers & Percentage \\
\hline \multicolumn{3}{|c|}{ Age (Yrs.) } \\
\hline $21-30$ yrs. & 12 & 33.3 \\
\hline $31-40$ yrs. & 8 & 22.2 \\
\hline $41-50$ yrs. & 9 & 25.0 \\
\hline$>50$ yrs. & 7 & 19.4 \\
\hline \multicolumn{3}{|c|}{ Gender } \\
\hline Male & 24 & 66.7 \\
\hline Female & 12 & 33.3 \\
\hline \multicolumn{3}{|c|}{ Educational Status } \\
\hline Illiterate & 1 & 2.8 \\
\hline Primary & 9 & 25.0 \\
\hline Secondary School & 11 & 30.6 \\
\hline Higher Secondary & 8 & 22.2 \\
\hline Graduate & 6 & 16.7 \\
\hline PG and above & 1 & 2.8 \\
\hline \multicolumn{3}{|c|}{ Occupation } \\
\hline Daily Labourer & 6 & 16.7 \\
\hline Farmer & 7 & 19.4 \\
\hline Private Business & 10 & 27.8 \\
\hline Govt Servant & 5 & 13.9 \\
\hline Housewife & 8 & 22.2 \\
\hline \multicolumn{3}{|c|}{ Relationship with Craniotomy Patients } \\
\hline Mother & 6 & 16.7 \\
\hline Father & 8 & 22.2 \\
\hline Wife & 1 & 2.8 \\
\hline Husband & 8 & 22.2 \\
\hline Daughter & 4 & 11.1 \\
\hline Son & 9 & 25.0 \\
\hline
\end{tabular}

In the 21 - 30 years age group there were 33.30 percent of craniotomy caregivers, in the 31 - 40 years age group there were 22.2 percent, in the 41 - 50 years age group there were 25 percent and 19.40 percent were over 50 years of age, 66.70 $\%$ of the caregivers of craniotomy patients were males and $33.30 \%$ were females. $2.80 \%$ of caregivers of craniotomy patients were illiterate and $2.80 \%$ were educated up to postgraduation and above, $25 \%$ of them were educated up to primary school, and $22.20 \%$ up to higher secondary school and $16.70 \%$ of the caregivers were graduate, $16.70 \%$ of caregivers of craniotomy patients were daily labourers, 19.40 $\%$ of them were farmers, $27.80 \%$ of them were doing business, $13.90 \%$ of them were government servants and $22.20 \%$ of the caregivers of craniotomy patients were housewives, $16.70 \%$ of caregivers of craniotomy patients were mothers, each 22.20
$\%$ of them were fathers and husbands, $2.80 \%$ of them were wives, $11.10 \%$ of them were daughters and $25 \%$ of them were sons respectively. In assessment with the level of knowledge score, shows that $22.22 \%$ of the caregivers of craniotomy patients were having poor level of knowledge score, $63.89 \%$ had average and $13.89 \%$ had good level of knowledge score, 0 $\%$ had an excellent level of knowledge score. The range of knowledge score was 2 - 10. Mean knowledge score was 6.02 \pm 2.06 and the mean percentage of knowledge score was $37.67 \pm 12.89$.

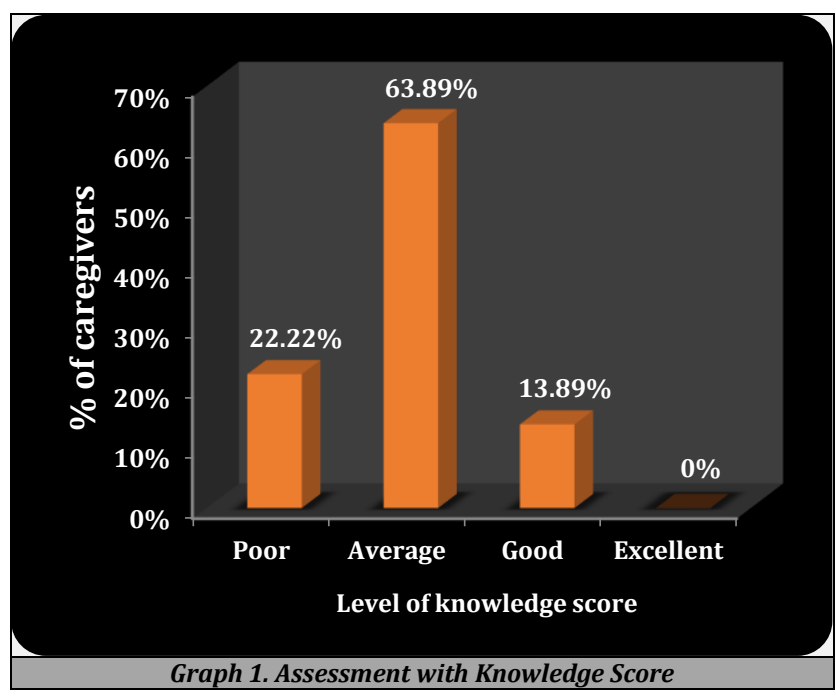

In assessment with the level of the practice score, shows that $22.22 \%$ of the caregivers of craniotomy patients were having average level of practice score, $75 \%$ had good and 2.78 $\%$ had good level of practice score, $00 \%$ had better level of practice score. The range of practice score was $6-11$. The mean practice score was $7.25 \pm 1.02$ and the mean percentage of practice score was $45.31 \pm 6.40$.

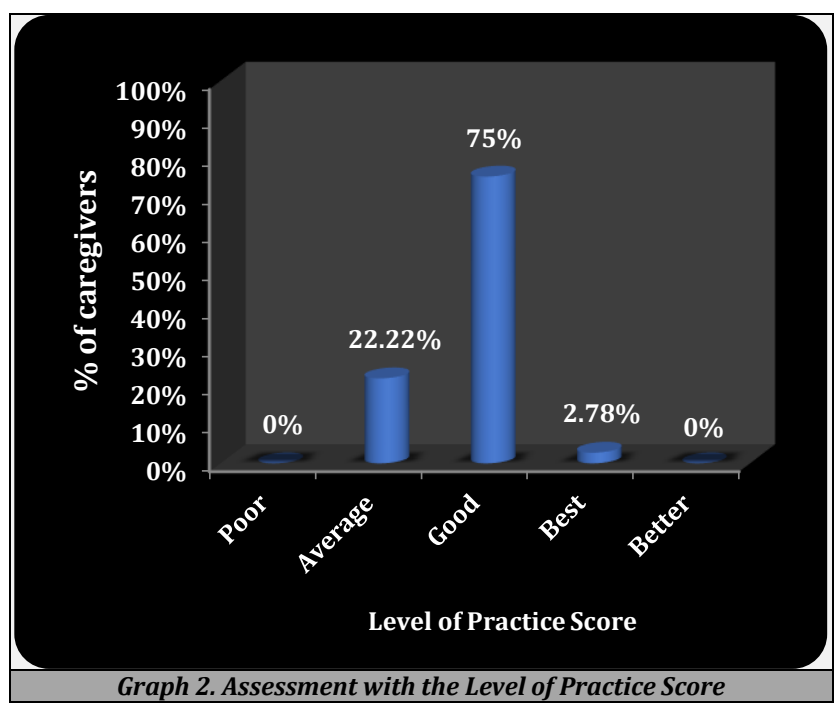

Associating awareness level with age in craniotomypatient care givers years. Tabulated ' $F$ ' values were $2.84(\mathrm{DF}=$ 3,32 ), far lower than measured ' $F$ ' i.e. 8.03 at a significant point of $5 \%$. Also, the measured ' $\mathrm{p}$ ' $=0.0001$ which was slightly less than the appropriate significance point, i.e. ' $p '=0.05$. Hence, it is perceived that age is statistically correlated with their information score in years of craniotomy caregiver's patients. 
Associating knowledge level with the educational status of craniotomy-patient caregivers. The tabled ' $F$ ' values were 2.53 ( DF = 5.30), which is far lower than the measured ' $F$ ' meaning level of 5.30 at 5 percent. Even the measured 'p' $=0.001$ which was slightly lower than the appropriate significance point i.e.' $p^{\prime}=0.05$. Therefore it is perceived that the educational status of craniotomy patient's caregivers is statistically correlated with their score of knowledge.

The association of knowledge score with the occupation of caregivers of craniotomy patients. Tabulated ' $F$ ' values were $2.61(\mathrm{DF}=4,31)$, far lower than measured 'F' i.e. 4.92 at a significance point of 5 per cent. Furthermore, the measured ' $p$ ' $=0.002$ which was slightly less than the appropriate significance point, i.e. ' $\mathrm{p}$ ' $=0.05$. Thus it is perceived that the occupation of craniotomy patient's caregivers is statistically correlated with their score of knowledge.

The practice association scores with a relationship with caregiver craniotomy patients. Tabulated ' $F$ ' values were 2.53 ( $D F=5,30$ ), which is less than the measured significance amount of ' $F$ ' i.e. 2.93 at 5 percent. Furthermore, the measured ' $p$ ' $=0.028$ was lower than the acceptable significance level i.e. ' $\mathrm{p}$ ' $=0.05$. Hence, it is perceived that the relationship with caregivers' and craniotomy patients is associated with their practice score statistically.

\section{DISCUSSION}

A thorough analysis of the literature suggested that most studies show that successful discharge preparation reduces the risk of complications, so during the patient's hospitalization, your time as a health care professional is responsible for teaching craniotomy treatment to caregivers, so we can reduce the risk of complication after discharge.

This research was modest to understand the level of caregiver's knowledge and practice about craniotomy care; caregivers play the major role in craniotomy care because patient fully depends on caregivers, that condition effective care reduces the risk complication.

Jisha. M, in 2007, conducted a research on effectiveness of health education on post- discharge home treatment awareness of patients following craniotomy. Craniotomy is a major surgical procedure in which the skull portion, called a bone flap, is removed for brain access. The research was performed in the ICU and Neurosurgical unit. Selecting the sample was achieved using a sequential sampling technique. The sample size was 22, patients who have undergone craniotomy for glioma decompression were the samples in this study. The investigator used a self-prepared questionnaire regarding the craniotomy home care, Malayalam version of the Modified Barthel Index, and a health education pamphlet on craniotomy home care was used to educate the patient after pre-test. The major findings of the study were, by health education patient's knowledge level was increased. By using the modified Barthel Index the investigator-assessed the functional disability, and modified Barthel Index was an effective tool that includes all aspects of activities of daily living of patients. 10

Sreejith, S. M. (2011). It was a descriptive study wherein caregivers of 30 patients who underwent craniotomy were conveniently selected on the fifth postoperative day. To assess the knowledge of home care among caregivers of patients after craniotomy. The data was analysed using Epi Info version 3.5.1. The study revealed that the mean knowledge score is higher among younger adults and people with high educational status. Approximate and timely caregiver education is necessary during hospitalization. So that optimum care is given to patients after discharge.

\section{CONCLUSIONS}

Knowledge of craniotomy care in craniotomy caregivers is insufficient. Important correlation between knowledge score was found with selected demographic variables such as age, education and occupation. Important correlation exists between practice score and selected demographic variables. Caregivers provide high-quality care to patients after craniotomy at their home. There is a need to educate older adults and care givers with low educational status to provide better care.

The study lacks generalization due to the limited number of samples. Therefore, studies using larger samples might be useful in validating the findings.

Data sharing statement provided by the authors is available with the full text of this article at jemds.com.

Financial or other competing interests: None.

Disclosure forms provided by the authors are available with the full text of this article at jemds.com.

\section{REFERENCES}

[1] Sreejith SM. A study to assess the knowledge of home care among caregivers of patients after craniotomy in SCTIMST, Trivandrum. 2011.

[2] Black MJ, Hawks HJ. Medical surgical nursing. Vol. 2. $7^{\text {th }}$ edn. Elsevier Publications 1992: pgs. 2161, 2051.

[3] Subba HK, Subba R. Knowledge on self care among COPD patients attending at Chitwan Medical College Teaching Hospital, Bharatpur. Journal of Chitwan Medical College 2014;4(3):34-7.

[4] Lopez AD, Mathers CD, Ezzati M, et al. Global and regional burden of disease and risk factors, 2001: systematic analysis of population health data. The Lancet 2006;367(9524):1747-57.

[5] Shiber JR, Macindoe C, Flower O, et al. Neurological emergencies. Emergency Medicine International 2012;2012:208193.

[6] Fry OM. Some aspects of the postoperative care of neurosurgical patients. The American Journal of Nursing 1935;1:16-8.

[7] Zanchetta C, Bernstein M. The nursing role in patient education regarding outpatient neurosurgical procedures. Axone 2004;25(4):18-21.

[8] Zanchetta C, Bernstein M. The nursing role in patient education regarding out patients neurosurgucal procedures. Canadian Journal of Neuroscience Nurses 2004;25(4):18-21

[9] Lewis SL, O’Brien PG, Heitkemper MM, et al. Medical surgical nursing - assessment and management of clinical problems. $7^{\text {th }}$ edn. Elsevier Publication 2007: pgs. 1464, 1516. 
[10] Jisha M. Effectiveness of health education on knowledge about post discharge home care of patients after craniotomy. SCTIMST, Trivandrum. 2007. 